\title{
Notas sobre a rotina: tempo, sofrimento e banalidade do poder na gestão de casos de pessoas desaparecidas no Rio de Janeiro
}

Notes on routine: time, suffering and the banality of power in the management of missing persons cases in Rio de Janeiro

\section{Letícia Carvalho de Mesquita Ferreira}

Brasil. Universidade Federal do Rio de Janeiro. Professora adjunta do Departamento de Antropologia Cultural (DAC) e do Programa de Pós-Graduação em Sociologia e Antropologia do Instituto de Filosofia e Ciências Sociais (IFCS) da Universidade Federal do Rio de Janeiro (UFRJ). ORCID: http://orcid.org/0000-0001-8466-5904. E-mail: leticiacarvalho@gmail.com.

\section{Resumo}

A partir de dados etnográficos sobre a administração de casos de desaparecimento de pessoas em duas repartições públicas, uma delegacia policial e um serviço de assistência social, analiso a experiência de Estado vivida por familiares de desaparecidos no estado do Rio de Janeiro, conferindo especial atenção para suas dimensões temporal e moral. Considerando que a busca por um familiar desaparecido é marcada por um tipo de espera bastante particular, marcado não pela passividade, mas pela permanente peregrinação por instituições e espaços públicos, reflito sobre o regime de ação que constitui essa espera e busco colocar em relevo seu aspecto moral, seu caráter rotineiro e sua relação com o sofrimento.

Palavras-chave: Pessoas Desaparecidas, Rotina, Tempo, Sofrimento.

\section{Abstract}

Drawing from ethnographic data on the administration of missing persons cases at a police station and a social service office, I analyze the experience of the state endured by relatives of missing persons in the state of Rio de Janeiro. I pay special attention to the temporal and moral dimensions of this experience. Considering 
that the search for a missing person is marked by a particular modality of waiting, characterized not by passivity, but by the permanent pilgrimage throughout institutions and bureaucracies, I reflect on the regime of action constituted by their waiting, and I try to highlight its moral aspect, its routine character and its relation to suffering.

Keywords: Missing People, Routine, Time, Suffering.

\section{INTRODUÇÃO}

"O desaparecimento é a quebra da rotina. É quando as coisas fogem do hábito, do comum, do cotidiano.” Foi assim que Cecília ${ }^{1}$ respondeu a uma pergunta minha, menos dirigida e mais compartilhada com ela em um evento nacional sobre o desaparecimento de pessoas no Brasil contemporâneo. Fundadora de uma associação de familiares de desaparecidos pioneira no país, Cecília é mãe de Flávia, desaparecida desde dezembro de 1995. O evento em que nos encontramos aconteceu em Boa Vista-RR, em novembro de 2010, e congregou gestores públicos, representantes de associações civis e organizações não governamentais (ONGs), policiais civis e militares de diferentes unidades da Federação e familiares de pessoas desaparecidas. Promovido pela ReDesap ${ }^{2}$, uma rede de organizações então coordenada pela Secretaria de Direitos Humanos da Presidência da República, o encontro teve como objetivo principal debater e traçar estratégias de prevenção e enfrentamento contra o desaparecimento de pessoas, passíveis de serem adotadas em todo o território

\footnotetext{
Para preservar as identidades de meus interlocutores de pesquisa, todos os nomes próprios mencionados neste artigo são fictícios.

2 Trata-se da Rede Nacional para Identificação e Localização de Crianças e Adolescentes Desaparecidos, conhecida por seus membros como ReDesap. A rede foi criada em 2002 no âmbito da Secretaria Especial de Direitos Humanos da Presidência da República (SDH/PR), mas formalmente instituída somente dia 5 de agosto de 2011, por meio da Portaria ${ }^{\circ}$ 1.520/2011 da SDH/PR. Segundo o documento, tem por finalidade "acompanhar a implementação de políticas públicas para a prevenção, localização e atendimento de crianças e adolescentes desaparecidos no país” (Artigo $1^{\circ}$ ).
} 
brasileiro. Esse evento foi um dos dezoito encontros nacionais, regionais e locais da rede em que estive presente na condição de pesquisadora.

Também intitulado desaparecimento $\mathrm{civil}^{3}$, o desaparecimento de pessoas era, já naquele momento, tema central de uma agenda de pesquisa etnográfica que venho desenvolvendo desde 2008. Interessada nas formas vigentes no país de "gestar e gerir" o desaparecimento (SOUZA LIMA, 2002), comecei a pesquisar o tema com um trabalho de campo em um setor da Polícia Civil do Rio de Janeiro, posteriormente estendido para eventos promovidos pela ReDesap em diferentes cidades do país (FERREIRA, 2015a) e, mais recentemente, para um programa de assistência social do governo estadual do Rio de Janeiro (FERREIRA, 2015b) 4 . Em todos esses espaços, busquei acompanhar sobretudo as rotinas administrativas dos servidores públicos que lidam com a questão, sejam eles policiais, assistentes sociais ou gestores públicos de órgãos estaduais e federais. O que se passa "do lado de lá" do balcão de diferentes repartições públicas que recebem queixas, relatos e demandas de familiares de crianças, adolescentes, adultos e idosos desaparecidos esteve sempre no centro dos meus interesses, o que não impediu - ao contrário, só tornou incontornável - que eu voltasse minha atenção também às práticas, narrativas, estratégias e

3 Oliveira (2007), em pesquisa pioneira no Brasil, cunha a expressão "desaparecimento civil" de modo a marcar a diferença entre o fenômeno mais geral do desparecimento de pessoas e o universo particular de casos passíveis de ser enquadrados no tipo penal internacional "desaparecimento forçado de pessoa", vulgarmente chamado de "desaparecimentos políticos". Definido no âmbito do Tribunal Penal Internacional em abril de 1998, e regulado pelo chamado Estatuto de Roma, por desaparecimento forçado de pessoas entende-se "a prisão, detenção ou sequestro de pessoas por um Estado ou por organização política, ou com a autorização, apoio ou aquiescência destes, seguidos da negativa de informar sobre a privação de liberdade ou dar informação sobre a sorte ou o paradeiro dessas pessoas, com a intenção de deixá-las fora do amparo da lei por um período prolongado. Esse conceito foi mantido no Estatuto definitivo, enquanto crime contra a humanidade." (JARDIM, 2011, p. 14). Para uma análise da definição de desaparecimento forçado de pessoas e da consequente categoria "desaparecido forçado" ou "detido-desaparecido", ver também Gatti (2011).

4 A referida pesquisa no setor da Polícia Civil do Rio de Janeiro e nos eventos da ReDesap foi desenvolvida durante meu doutoramento no PPGAS/Museu Nacional/UFRJ, encerrado em outubro de 2011 (FERREIRA, 2015a). Já a pesquisa no programa de assistência social do mesmo estado encontra-se em andamento, no âmbito do projeto "Dramas de família nos balcões da burocracia: a administração institucional de casos de desaparecimento de crianças e adolescentes no estado do Rio de Janeiro". Esse projeto conta com o apoio da Fundação Carlos Chagas Filho de Amparo à Pesquisa do Estado do Rio de Janeiro (Faperj), por meio do programa Jovem Cientista do Nosso Estado (JCNE), edital 03/2017. Para proteger a identidade de meus interlocutores de pesquisa que são servidores públicos, seja na polícia, seja na assistência social, não identificarei as repartições públicas e serviços específicos em que realizei trabalho de campo. 
formas de apresentação de si acionadas por aqueles que procuram essas repartições em função do desaparecimento de um parente, familiar ou conhecido.

A despeito das diferenças que separam os espaços institucionais por onde tenho transitado, que vão desde amplos salões de convenção e solenes gabinetes de gestores públicos até exíguas repartições que prestam atendimento direto a cidadãos, algo os aproxima de modo incontornável: os questionamentos regularmente levantados pelos diversos agentes que lidam com o desaparecimento de pessoas no Brasil, seja por circunstâncias pessoais, seja por atribuições profissionais. Esses questionamentos colocam em relevo, entre outras "faltas" e "ausências" atribuídas à questão, que o desaparecimento não é um crime e não possui qualquer definição clara que sirva de diretriz a todos aqueles que tratam do problema no país, além de não estar retratado em estatísticas confiáveis e não ser alvo de políticas públicas específicas de alcance nacional. No vácuo constituído por tantas negativas, múltiplas formas de abordar o problema são constituídas e justificadas, casos bastante heterogêneos são sistematicamente reunidos, e importantes divergências sobre quem é responsável pela prevenção e pela gestão do fenômeno são estabelecidas, muitas vezes na forma de duras acusações cruzadas entre familiares de desaparecidos, gestores de políticas públicas e policiais civis.

Foi diante desse quadro de ausências, negativas e divergências que, no último dia do encontro nacional da ReDesap em Boa Vista, compartilhei com algumas das pessoas de quem me aproximei uma indagação sobre se e como, afinal, poderíamos definir o desaparecimento de pessoas. E foi dizendo que o desaparecimento "é quando as coisas fogem do hábito, do comum, do cotidiano" que Cecília respondeu à minha pergunta, apontando algo sugerido também na literatura disponível sobre o tema. Para Hogben (2006), por exemplo, o desaparecimento propicia reflexões fundamentais sobre o tempo e a repetição rotineira de atividades como dispositivos que ordenam relações. Analisando apelos e relatos em torno de casos divulgados em meios de comunicação britânicos, a autora sustenta que, do ponto de vista de familiares de desaparecidos, o desaparecimento é um evento intersticial, saturado de incertezas, que se traduz em dor e espera e que inaugura uma temporalidade: o presente 
estendido. Implica, assim, a suspensão dos chamados calendários privados (SACK apud HOGBEN, 2006), já que esvazia de sentido marcos temporais pautados em relações e trajetórias pessoais e familiares 5 .

Atualizando - ou tentando atualizar - seu calendário privado, Cecília costuma contar quantos anos, meses e dias se passaram desde que sua filha desapareceu. Quando nos encontramos em Boa Vista, fazia 14 anos, 10 meses e 13 dias que Flávia, então uma adolescente de 13 anos, saiu de casa para ir a uma festa de aniversário e nunca mais retornou. Um dos dias daquele evento em Roraima, aliás, coincidiu com o aniversário da própria Cecília. Reunidos em torno de um bolo, alguns dos presentes demos a ela uma lembrança e cantamos "Parabéns pra você". Ainda que lisonjeada e contente com a homenagem, antes de cortar o bolo Cecília afirmou que, desde que Flávia desapareceu, datas como seu aniversário perderam completamente o sentido. Ela tinha o hábito de comemorá-las, mas depois do desaparecimento da filha não fez mais festas.

Essa não foi a única mudança de hábito que o fato provocou em sua vida, porém. Em função do desaparecimento de Flávia, Cecília, que nunca tinha ido a uma delegacia, já foi não só a uma, mas a muitas repartições policiais. Assim como costuma contar quanto tempo se passou desde o dia em que sua filha saiu de casa para não mais voltar, ela também costuma narrar, em ocasiões tão distintas quanto uma conversa informal e uma audiência pública, como foi o atendimento que recebeu na primeira (de muitas) delegacia em que esteve. $\mathrm{Na}$ ocasião, o policial que a recebeu e ouviu seus relatos sobre o sumiço de Flávia logo lhe perguntou se a adolescente não teria fugido "com um namoradinho" e se não era usuária de drogas. Essas perguntas causaram em Cecília um sentimento de revolta que, com efeito, passou a acompanhar o sofrimento que ela experimenta desde então pela falta de notícias de sua filha.

Relatos como os de Cecília articulam três questões que estão no centro da reflexão que proponho neste artigo: o tempo, o sofrimento de ter um filho

Conforme Hogben (2006), calendários privados são dispositivos que permitem localizar eventos de acordo não com parâmetros genéricos, mas sim com determinadas relações. Por meio deles, mesmo eventos de natureza coletiva, distantes e que não implicam diretamente determinado sujeito são inscritos e experimentados no marco de suas relações, permitindo ilações como "Kennedy foi assassinado duas semanas depois que ficamos noivos", para usar o exemplo evocado pela autora (HOGBEN, 2006, p. 329). 
desaparecido e a rotina de peregrinação por repartições e eventos públicos que o desaparecimento inaugura na vida daqueles que procuram por alguém. A partir de dados etnográficos sobre o atendimento a familiares de desaparecidos em duas repartições em que fiz trabalho de campo, uma delegacia policial e um serviço de assistência social, busco refletir sobre a experiência de Estado vivida por familiares de desaparecidos no estado do Rio de Janeiro, dando especial atenção para suas dimensões temporal e moral. Considerando que a busca por um familiar desaparecido é marcada por um tipo de espera bastante particular, marcado não pela passividade, mas sim pela permanente peregrinação por instituições públicas, analiso os sentidos da experiência de Estado que constitui essa espera e busco colocar em relevo seu aspecto moral, seu caráter rotineiro e sua relação com o sofrimento.

Para tanto, parto de duas premissas gerais sobre a relação entre tempo e poder: em primeiro lugar, a ideia de que o tempo, sobretudo em seu ocultamento e manipulação, é uma dimensão chave de dinâmicas de dominação vigentes no cotidiano de repartições públicas, razão pela qual esperar pelo desfecho de demandas colocadas nesses espaços não é um ato desprovido de significados, e menos ainda de consequências (AYUERO, 2011; VIANNA, 2015). E, em segundo lugar, a noção de que a imposição de ações rotineiras, previsíveis e regulares é um elemento central para a reprodução de sistemas de dominação, conforme propõe Achille Mbembe (1992) por meio da noção de banalidade do poder.

\section{OS RITMOS E A DIMENSÃO MORAL DA ESPERA NA GESTÃO POLICIAL DOS CASOS}

Muito embora relações sociais demandem atenção continuada aos objetos e eventos mais ordinários da vida cotidiana, segundo Das (2007) certo impulso teórico nos conduz, enquanto cientistas sociais, a escapar do rotineiro e tratar de acontecimentos grandiloquentes, que seriam extraordinários e destoantes em relação ao cotidiano. Como mostram pesquisas da autora junto a vítimas 
de episódios de violência coletiva, contudo, mesmo os chamados eventos críticos (DAS, 1995) estão sempre enraizados no ordinário, ainda que não possam ser capturados em toda sua força pelo repertório de ação e pensamento disponível no cotidiano - ou, em suas palavras, pela "gramática do ordinário" (DAS, 2007, p. 7). Dito de outro modo, a experiência de um evento crítico e de seus efeitos disruptivos é, ela mesma, rotineira, já que aquele que é atravessado por ele também o vivencia à medida que busca reabitar seu cotidiano, no que seria um delicado trabalho de autocriação (DAS, 2007).

A contagem dos anos, meses e dias da duração do desaparecimento de Flávia, exercício de que Cecília se ocupa regularmente, pode ser compreendida nesses termos. Ademais, a própria presença dela no evento em que a encontrei, na condição de mãe de uma desaparecida e fundadora de uma associação que presta assistência a outras mães e familiares na mesma situação, também pode ser assim analisada. A atuação militante e o engajamento sistemático em ONGs, movimentos sociais, associações e eventos públicos, como demonstram trabalhos como os de Araújo (2008, 2014), Lacerda (2015), Leal (2017) e França (2018), são atividades desempenhadas com notável regularidade por mães, pais e demais familiares de desaparecidos no sentido de integrar às suas vidas o desaparecimento dos seus ${ }^{6}$. Tais trabalhos têm demonstrado, aliás, o papel fundamental que atividades desse tipo desempenham na própria constituição de "casos" e de "causas" com repercussões de ordens diversas.

Somando-se às reflexões desses autores, outros trabalhos (FERREIRA, 2015a, 2015b; OLIVEIRA, 2007; OLIVEIRA, 2008) têm focado outras atividades, em certo sentido menos visíveis, embora não menos sistemáticas, constitutivas do processo pelo qual o desparecimento de um ente querido é integrado à vida ordinária daqueles que esperam por seu retorno: as visitas recorrentes a diferentes repartições públicas e as interações, em cada uma delas, com servidores como policiais civis, assistentes sociais, conselheiros tutelares e técnicos

\footnotetext{
Importa notar que esses trabalhos renovam e desenvolvem, a partir de questões etnográficas próprias e diretamente relacionadas ao desaparecimento de pessoas, a temática mais abrangente das relações entre sofrimento e política no âmbito de mobilizações sociais de familiares de vítimas de violências diversas, trabalhada anteriormente por Birman (2004) e, mais recentemente, também por Vianna e Farias (2011), Farias (2015) e Vianna (2015), entre outros pesquisadores.
} 
de diferentes áreas da administração pública. Hospitais, institutos de medicina-legal, delegacias de polícia, órgãos de assistência social, conselhos tutelares e instituições de acolhimento são visitados com impressionante regularidade por parentes e familiares de desaparecidos, tornando-se verdadeiros checkpoints (JEGANATHAN, 2004) ${ }^{7}$ de peregrinações tão rotinizadas quanto extenuantes, iniciadas logo que se constata um desaparecimento e não necessariamente encerradas com a localização do desaparecido.

São essas peregrinações e interações que convertem, ora com mais, ora com menos efetividade, atos e fatos bastante heterogêneos em "casos de desparecimento de pessoa", assim registrados e administrados em diferentes instituições. Ao mesmo tempo, são elas que convertem aqueles que relatam esses casos a autoridades diversas em "familiares de desaparecidos". Nesse sentido, fugas do lar, acidentes fatais cujas vítimas não são identificadas, separações não consensuais, raptos, assassinatos seguidos de ocultação de cadáveres, entre tantas outras possibilidades, tornam-se igualmente "casos de desaparecimento de pessoa" à medida que são comunicados e registrados em repartições policiais, programas de assistência social e outras repartições. No mesmo movimento, pais, companheiros, conhecidos, vizinhos, filhos e mães de pessoas tidas como desaparecidas tornam-se igualmente "familiares de desaparecidos".

O ponto central em questão aqui é que demandar, desvendar, responder e muitas vezes contestar "atividades estatais aparentemente mundanas" (SHARMA; GUPTA, 2006, p. 9) levadas a cabo em instituições diversas que administram "casos" torna-se, desde a constatação de um desaparecimento, parte fundamental da rotina dos "familiares de desaparecidos" e de seus calendários privados. Como indicam as falas de Cecília, cada pergunta ou insinuação ouvida de um policial, cada documento produzido ou requisitado em um

\footnotetext{
A partir de etnografia na cidade de Colombo, no Sri Lanka, Jeganathan constrói o checkpoint como um objeto antropológico especialmente revelador dos sentidos e efeitos de práticas estatais de assujeitamento. Checkpoints são pontos ou barreiras estatais, mais ou menos permanentes, onde identidades são "checadas" segundo o arbítrio de funcionários públicos diversos, normalmente de baixo escalão. Na definição etnográfica do autor, iluminadora para a análise de outros tipos de pontos, barreiras e instituições estatais, "na sua forma mais básica e ordinária, um checkpoint é formado por soldados, homens ou mulheres de baixo escalão, que interrompem o fluxo de tráfego geralmente veicular, mas muitas vezes também pedestre, para fazer perguntas a quem passa. As interrogações envolvem questões de identidade" (JEGANATHAN, 2004, p. 69, tradução nossa).
} 
balcão de delegacia, cada fila, demora ou recusa de atendimento em um hospital e cada decisão tomada em um conselho tutelar ou instituto de medicina legal, seja por um policial, assistente social ou recepcionista, inscreve-se na temporalidade específica engendrada pelo desaparecimento e, muitas vezes, torna-se parte inextricável da própria experiência disruptiva de ter um filho, companheiro, pai ou parente desaparecido. Além disso, cada um desses elementos que vão compondo o caso desdobram a espera pelo retorno do desaparecido em novas modalidades de espera: a espera pela investigação por parte da polícia; a espera por um cartaz com a fotografia do desaparecido a ser confeccionado no serviço de assistência social; a espera pela checagem nas listas de "entrada" de cadáveres em institutos médico-legais; e, o que não é de somenos importância, a espera pelo atendimento propriamente dito em qualquer dessas instituições, muitas vezes adiado por servidores públicos que entendem que um caso só pode ser considerado "real" depois de 48 horas sem notícias do desaparecido, como comentarei a seguir.

Como mostra Vianna (2015), a espera e, sobretudo, a angústia que a acompanha em contextos de demanda e de luta por direitos, serviços, justiça e/ou reparação mediante instituições e agentes públicos, não pode ser desvinculada da configuração moral mais ampla que permeia "casos", situações e conflitos que motivam tais demandas e lutas. Avaliações morais dos sujeitos e dos acontecimentos envolvidos em casos administrados por instituições e agentes públicos são muitas vezes feitas em termos da tenacidade, da resiliência e de um suposto engajamento permanente a ser demonstrado por familiares das vítimas e demais envolvidos nas situações em questão. No contexto de pesquisa da autora (VIANNA, 2015; VIANNA; FARIAS, 2011), essa tenacidade, demonstrada com participação constante de familiares de vítimas de violência policial em atos e manifestações públicas e presença regular em audiências, julgamentos, visitas à Defensoria Pública e a outras repartições, é tratada como um indicador do quão ilibados e moralmente corretos são seus filhos ou outros parentes em nome de quem falam, lutam e buscam por justiça.

Esse tipo de avaliação também opera, com suas próprias características, na administração policial de casos de desaparecimento. Familiares de 
desaparecidos que procuram pelos serviços da polícia têm sua tenacidade submetida a julgamento desde o momento em que chegam a uma delegacia e fazem o que costuma ser sua primeira solicitação: um registro da ocorrência. A solicitação do documento é fundamental não só porque é ele que dá início à investigação do caso, mas também porque ele é encarado pelos familiares como evidência do cuidado e da preocupação que têm para com o desaparecido. Relatos de Maria, mãe de Renata, desaparecida em 1992 quando tinha 13 anos de idade, deixam claro como isso se dá. Já encontrei Maria em diferentes espaços e momentos de minha trajetória de pesquisa, e em diversas ocasiões a ouvi narrar sua experiência de atendimento em delegacias. Maria costuma destacar que sua filha desapareceu dia 12 de novembro de 1992 e que, em poucas horas, ela compareceu à repartição policial para comunicar o ocorrido. Entretanto, o caso só foi registrado dia 18 de novembro, depois de algumas idas e vindas de Maria entre a delegacia e sua casa, o que gerou um documento com data seis dias posterior a data do desaparecimento. Para Maria, "ficou parecendo que eu não me importei com o desaparecimento da minha filha $\mathrm{e}$ isso não é verdade, senão eu não estaria lutando por ela há tantos anos."

O adiamento da confecção do registro de ocorrência é algo tão rotinizado em delegacias que, entre familiares de desaparecidos e gestores públicos que tratam do tema, circula uma expressão para sintetizá-lo: "o mito das 48 horas". Esse "mito" refere-se à praxe em repartições policiais de solicitar que familiares de desaparecidos aguardem um intervalo de dois dias para confirmar que o desaparecimento que gostariam de comunicar à polícia é "real" ou, como ouvi de policiais civis, "um verdadeiro caso de desaparecimento", e não um mero desencontro ou conflito entre pessoas que as afasta por algumas horas ou dias. Antes de expirado esse prazo, para os policiais ainda não haveria caso a registrar nem investigação policial a fazer, cabendo à família esperar o tempo passar e, só depois, retornar à delegacia ${ }^{8}$. Não obstante a difusão do "mito" pelas

\footnotetext{
Para combater o "mito", mas apenas diante de casos envolvendo crianças, adolescentes e deficientes, em julho de 2001 foi sancionada pelo então governador do estado do Rio de Janeiro a chamada "Lei Estadual de Busca Imediata", que "determina à autoridade policial e aos órgãos de Segurança Pública a busca imediata de pessoa desaparecida menor de 16 (dezesseis) anos ou pessoa de qualquer idade portadora de deficiência física, mental e/ou sensorial" (RIO DE JANEIRO, 2001). Lei semelhante, mas válida para todo
} 
repartições policiais, os relatos de Maria revelam que às vezes a espera imposta às famílias é ainda mais longa do que os dois dias de praxe.

Demonstrar tenacidade, insistir, retornar à delegacia e efetivamente obter um registro de ocorrência não encerra, porém, a avaliação moral que recai sobre os familiares de desaparecidos - e que se estende para os próprios desaparecidos e para a veracidade do "caso". No momento da confecção dos registros, policiais mobilizam enquadramentos morais bastante padronizados principalmente em relação aos desaparecidos, afirmando com frequência que meninas e jovens mulheres que desaparecem "devem ter fugido com o namoradinho", como ouviu Cecília, ou "estão se prostituindo por aí", como já ouvi de outras mães em eventos promovidos pela ReDesap. Já os meninos e homens jovens ou adultos são rapidamente colocados sob as figuras do "bandido", "traficante" ou até do "criminoso de meia-tigela", como me foi dito na delegacia em que realizei trabalho de campo. Narrativas morais padronizadas sobre vítimas e sobre seus familiares, como nos adverte Vianna (2015, p. 416), colonizam as histórias individuais colocadas em cena em repartições e eventos públicos, tornando palpáveis as assimetrias sociais e políticas que marcam as vidas daqueles que falam e daqueles em nome de quem falam. Na gestão policial de casos de desaparecimento, vencido o adiamento da produção dos registros de ocorrência, esse processo começa imediatamente a operar, marcando a nova espera que se inicia então: a espera pelas investigações em torno dos casos e, com ela, a expectativa por uma solução.

Embora os familiares depositem essa expectativa no trabalho policial, ao mesmo tempo são encarados pelos policiais responsáveis pelas investigações como os únicos que detêm de fato a capacidade de resolver os casos. Como me disse o policial Fernando, interlocutor fundamental de minha pesquisa em delegacia, “quem encontra um desaparecido é a própria família”. Isso acontece, para ele, em dois sentidos: ou são as informações fornecidas pela família, e só elas, que habilitam policiais a localizar desaparecidos; ou, como ocorreria na maior parte dos casos, são familiares que efetivamente encontram o

o território nacional, foi sancionada pelo presidente da República em dezembro de 2005 e incorporada ao Estatuto da Criança e do Adolescente (ECA). 
desaparecido, já que fazem suas próprias buscas em lugares conhecidos e entre pessoas conhecidas enquanto a polícia está fazendo suas investigações. Para Fernando, "se a família não comunica, a polícia não vai investigar, e se a família não colabora, a polícia não tem nem por onde começar”.

Essas falas revelam parte de um conjunto de compromissos que são impostos aos familiares no momento em que solicitam o registro de ocorrência do caso e, com ele, o início das investigações policiais. Além de fornecer informações e "colaborar", dois compromissos fundamentais que recaem sobre eles e não aparecem nos enunciados de Fernando têm destaque por sua recorrência: o de seguir fazendo buscas "por conta própria", como dizem os policiais; e, se essas buscas forem bem-sucedidas, o de retornar à delegacia para informar que encontraram o desaparecido. Uma queixa frequente de policiais que lidam com desaparecimentos é a de que, embora cumpram o primeiro compromisso e "quase sempre achem quem procuram", os familiares não avisam nas delegacias que já encontraram seus parentes, o que alimenta uma forte desconfiança e uma clara antipatia por parte dos agentes. "Eles nem se dão ao trabalho de nos avisar", como ouvi de Fernando logo que iniciei trabalho de campo na delegacia em que ele estava lotado. Nesse sentido, o processo que se inicia com o registro de ocorrência feito na delegacia agrega à avaliação moral dos envolvidos e da veracidade do caso os elementos da desconfiança e da antipatia. É nesse cenário emocional e moralmente carregado, marcado pelo empreendimento incansável de buscas "por conta própria", que se faz a espera pela solução de um caso.

As buscas "por conta própria" feitas pela família muitas vezes começam já na delegacia. O caso de um idoso a cujos documentos tive acesso, comunicado na delegacia por sua filha, evidencia isso com clareza. Depois de relatar ao policial que primeiro a atendeu que seu pai sofria de perdas de memória e que deveria estar perambulando pelas ruas do bairro onde morava, a mulher recebeu do agente um catálogo telefônico e a instrução de primeiro procurá-lo através de telefonemas a lugares e pessoas que julgasse úteis. O policial disponibilizou uma linha telefônica da delegacia para que ela fizesse buscas desse modo, e só depois produziu o registro de ocorrência. Passados alguns dias, o 
idoso foi encontrado por um vizinho e sua filha voltou à delegacia para informar que o caso estava solucionado. As informações registradas na ocasião revelam que o compromisso de buscar o desaparecido pode ser imposto aos familiares de tal forma que parece ser necessário justificar sua ida inicial à polícia:

Quando procurou esta DP [delegacia policial] para fazer o registro do desaparecimento de seu pai foi pelo fato de estar desesperada e achar que se seu pai acabasse sendo achado por alguém que o conduzisse até uma delegacia policial, poderia ser que as demais tomassem conhecimento de que a família o estava procurando?.

A condição "desesperada" da filha do desaparecido e a necessidade de justificação para que tenha buscado a polícia respondem, portanto, aos compromissos impostos aos familiares pelos policiais a quem comunicam os casos, de quem esperam um trabalho de investigação e por quem são vistos com desconfiança e antipatia. Enquanto esperam que a polícia trabalhe, familiares devem procurar os desaparecidos e, caso encontrem, procurar também a polícia e notificá-la.

Os compromissos impostos aos familiares não cessam quando o caso é solucionado. Independentemente da forma pela qual o desaparecimento é resolvido, seja pelas buscas dos familiares, seja pelo trabalho investigativo dos policiais, novos compromissos são incutidos nos primeiros pelos últimos. É praxe que policiais solicitem não só que os familiares compareçam às delegacias para confirmar dados e informações sobre os desaparecidos e para assinar documentos sobre o encerramento do caso, como também que garantam que documentos de identidade dos desaparecidos sejam feitos ou atualizados, demandando que todos procurem novas repartições e checkpoints a partir daquele momento, como os postos do Detran - que emitem RGs no estado do Rio de Janeiro. A solução de um caso, portanto, não necessariamente implica o fim da peregrinação dos familiares por instituições públicas. Além disso, outras solicitações são feitas pelos policiais e muitas vezes registradas em documentos

9 Os documentos relativos a esse caso compõem a Sindicância 042/08 do Serviço de Descoberta de Paradeiros da antiga Delegacia de Homicídios do Rio de Janeiro, uma das repartições em que realizei trabalho de campo. 
no momento em que a solução do caso é oficializada: a recomendação para que controlem o comportamento dos desaparecidos, sabendo sempre onde estão, para onde irão e a que horas devem retornar para suas casas, evitando assim que desapareçam novamente. Essa recomendação, que carrega consigo a culpabilização da família pela própria ocorrência daquele caso e de eventuais casos futuros envolvendo a mesma pessoa, é especialmente frequente em desparecimentos de crianças e adolescentes.

Por tudo isso, pode-se dizer que a espera pelo trabalho da polícia diante de casos de desaparecimento é, mais que um ato ou uma disposição passiva dos familiares de desaparecidos, um regime de ação mais amplo: um regime de ação ritmado pelas interações com agentes e repartições públicas, dotado de uma forte dimensão moral e caracterizado pela realização incessante não só de repetidas idas a delegacias e outras instituições, até mesmo depois que o caso é encerrado, mas também de buscas feitas "por conta própria". Trata-se, enfim, de um regime de ação bastante ativo, muitas vezes até extenuante, em que os sujeitos são submetidos a um intenso escrutínio moral e acumulam um conjunto de compromissos e culpas que se espraiam pelas duas temporalidades de que fala Vianna (2015, p. 414): o "tempo da luta", caracterizado pelas idas constantes a instituições e espaços públicos, e o "tempo familiar", que corre na vida cotidiana, no interior das casas e das relações mais íntimas.

\section{ACOLHIMENTO, REGULARIDADE E URGÊNCIA NA GESTÃO ASSISTENCIAL DOS CASOS}

Se "o sofrimento é uma experiência social que pode ser intensamente agravada pelas modalidades de resposta oferecidas por poderes políticos, econômicos e institucionais a determinados problemas sociais" (KLEINMAN; DAS; LOCK, 1997, p. IX), os dados etnográficos apresentados sobre a gestão policial de casos de desaparecimento revelam algumas das formas pelas quais esse agravamento pode se dar. Não é sem razão, portanto, que mães e outros familiares de desaparecidos, como Cecília, que se reúnem em associações, 
movimentos sociais e ONGs dedicadas ao tema, articulam a dor de ter um filho desaparecido às dores provocadas pela desconfiança com que são atendidos em delegacias, à angústia de ter que esperar longos dias para obter um registro de ocorrência, ao cansaço de caminhar pela cidade procurando por seus parentes e, ainda, ao sofrimento de ver o tempo passar sem obter qualquer resposta. Não é sem razão, enfim, que esses sujeitos associam as dores e sofrimentos que se sobrepõem quando um ente querido desaparece aos dois elementos centrais deste artigo: por um lado, a rotina de atendimentos em repartições públicas como as delegacias, que passa a compor seu dia a dia e a expô-los a um intenso escrutínio moral; e por outro, o tempo, tornado especialmente visível no regime de ação em que consiste a espera inaugurada pelo desaparecimento.

No estado do Rio de Janeiro, um serviço de assistência social instituído no começo dos anos 1990, dedicado ao desaparecimento de crianças e adolescentes e atualmente inscrito no âmbito da Secretaria de Desenvolvimento Social e Direitos Humanos, é encarado por muitos familiares de desaparecidos como uma instituição que destoa, tanto por sua forma de atuar quanto pelo tipo de serviço que presta, das demais repartições que passam a compor a rotina de atendimentos a que são submetidos a partir do desaparecimento. As ações principais do serviço são receber os familiares, registrar os casos em prontuários e recolher e reproduzir retratos dos desaparecidos. Esses retratos são colocados em circulação na forma de cartazes e outros materiais e artefatos gráficos e audiovisuais distribuídos por todo o país a partir de parcerias e convênios já longevos entre o serviço e um conjunto de empresas privadas e instituições públicas. Nesses cartazes e demais materiais, encontram-se os retratos de crianças e adolescentes desaparecidos cadastrados lá, o número de telefone do serviço e as logomarcas das empresas e parcerias envolvidas na sua produção e distribuição. A partir da divulgação dos retratos, o serviço espera receber telefonemas com informações que possam auxiliar na solução dos casos. Tais informações são chamadas internamente de "denúncias" e, depois de avaliadas em sua possível veracidade e pertinência, costumam ser repassadas tanto para as famílias dos desaparecidos quanto para a delegacia em que o caso estiver registrado. A propósito, todo caso cadastrado no serviço deve 
necessariamente ter sido registrado antes em uma repartição policial, sendo a apresentação do registro de ocorrência um requisito para que a foto do desaparecido seja incluída em seus cartazes.

Além da ampla divulgação dos cartazes feita pelo próprio serviço, os familiares atendidos lá recebem exemplares desses materiais para fazer a divulgação do retrato dos seus desaparecidos "por conta própria”, como também é dito naquela repartição. Assim que um lote de cartazes entregue aos familiares acaba, eles costumam retornar à casa onde o serviço funciona para solicitar mais material. Esse é um pedido costumeiro ali, que leva muitos familiares ao serviço e que nunca vi ser negado por qualquer dos funcionários que conheci durante meu trabalho de campo. Esses retornos dos familiares ao serviço acontecem com regularidade, e são ocasiões em que os funcionários, assistentes sociais em sua quase totalidade, pedem-lhes atualizações sobre os casos, fazem pequenas anotações nos prontuários e lhes dão conselhos e opiniões sobre o que pode ter ocorrido e sobre como lidar com as dores e problemas que o desaparecimento lhes trouxe. Não é raro que esses funcionários saibam os nomes dos familiares que frequentam a casa em busca de reposição do material de divulgação, bem como os nomes dos desaparecidos que cada um deles busca e os enredos de cada um de seus casos. Mais do que isso, não é raro que saibam identificar o rosto de cada desaparecido nos cartazes, fazendo com notável rapidez sua conexão com um pai, uma mãe, um tio ou seja quem for que frequente a casa. Como me disse o tio de um jovem desaparecido que conheci na antessala do serviço, "o pessoal aqui é muito acolhedor".

Além do acolhimento ofertado aos que lhes procuram regularmente, em datas especiais os funcionários do serviço promovem pequenos eventos e convidam alguns dos familiares por eles atendidos para confraternizações. Em dezembro de 2013, quando havia recém-iniciado a pesquisa de campo em suas instalações, vi esse acolhimento sendo rapidamente estendido a mim, ainda que fosse apenas uma pesquisadora interessada no trabalho feito ali: fui convidada a participar de um almoço de Natal promovido pelo serviço em uma churrascaria próxima à casa onde ele funciona. Além dos funcionários do serviço e de mim, cerca de quinze familiares de desaparecidos estavam presentes, em 
sua maioria mães, e todos os que me foram apresentados por Gustavo, então gerente do serviço, foram identificados pelo nome e pelo nome do desaparecido a quem buscavam. Sobre alguns, ainda, Gustavo destacou informações que sabia de cor sobre os casos de seus filhos ou teceu elogios diretos, como "Essa é a mãe da Liliana, uma daquelas cinco meninas que desapareceram juntas, sabe?", e "Essa mulher é especial, uma guerreira, você precisa ouvir a história dela".

Porque "acolhedor", ainda que passe a integrar o duro itinerário de peregrinações regulares dos familiares de desaparecidos, esse serviço oferece um tipo de atendimento que lhes agrada. Além disso, sua ação principal de produzir e divulgar os cartazes e demais materiais com os retratos dos desaparecidos é vista pelos familiares como uma possibilidade concreta de facilitar a solução dos casos, sendo depositária de grandes esperanças - muito embora pesquisas sobre cartazes desse tipo revelem sua pouca eficácia na resolução de casos individuais (LAMPINEN; ARNAL; HICKS, 2008). Como as redes de distribuição dos cartazes se estende por todo território nacional, fazendo com que retratos de crianças que viviam em qualquer lugar do estado do Rio de Janeiro cheguem a regiões distantes de outras unidades da Federação, os familiares acreditam que as chances de seus desaparecidos serem encontrados aumentam a cada redistribuição do material. Por isso mesmo, pais e mães de desaparecidos de outros estados frequentemente entram em contato com o serviço e solicitam a inclusão das fotos de seus filhos nos cartazes, pedindo de seus funcionários, com sucesso, que abram exceções em relação a suas atribuições - restritas, por definição, a casos ocorridos no Rio de Janeiro. Um dos casos que acompanhei mais de perto durante o trabalho de campo lá, o desaparecimento de Pedro, de três anos idade, aconteceu no interior do estado de São Paulo e foi excepcionalmente incluído nas campanhas de divulgação do serviço a pedido de seu pai. O caso tinha chamado a atenção de Gustavo, gerente do serviço, "pela emoção do pai, que ligou pra gente muitas vezes e até veio aqui", e era objeto frequente de conversas entre ele e seus colegas de trabalho. Tanto quanto as práticas regulares de atendimento adotadas pelos funcionários, exceções como essa, feitas sob justificativas relacionadas à insistência do familiar do desaparecido, são evidências do caráter “acolhedor” do serviço, 
ativo mesmo diante de casos que estariam fora de sua alçada, e da incidência, também ali, de uma avaliação moral dos familiares semelhante à que acontece em repartições policiais, já que aprecia sua tenacidade e capacidade de insistir.

Nesse sentido, não obstante as características vistas como positivas pelos familiares que procuram o serviço, também ali os procedimentos de atendimento adotados de praxe acionam um intenso exercício de avaliação moral a que são submetidos não só os que procuram pelos desaparecidos, mas também os próprios desaparecidos e seus casos. Somando-se às exceções justificadas pela insistência, evidência clara disso é o primeiro formulário que deve ser preenchido sobre qualquer caso cadastrado lá, onde há campos em que os funcionários devem obrigatoriamente assinalar, mediante uma lista de perguntas, se na família do desaparecido há: espancamento, alcoolismo, uso de tóxicos, violência doméstica, abuso sexual, maus tratos. Após essa sequência de categorias, indicativas de parâmetros a partir dos quais os familiares, os desaparecidos e os próprios casos de desaparecimento são apreciados no serviço, o formulário dispõe ainda de espaço para que os funcionários registrem se os pais do desaparecido trabalham e, caso trabalhem, se têm carteira assinada.

Soma-se a esse escrutínio, ainda, o fato de que gradativamente os familiares e suas casas tornam-se objeto de ações diversas, que vão desde telefonemas, conversas e processos sutis de aconselhamento muitas vezes demandados por elas e ocorridos nas instalações do serviço, chegando até às chamadas "visitas domiciliares", às quais os familiares são submetidos involuntariamente. Essas visitas têm como finalidade averiguar as condições socioeconômicas e habitacionais em que eles vivem, bem como as expectativas e os sentimentos que o desaparecimento possa ter provocado em cada um dos familiares do desaparecido e em suas relações. Relatórios dessas visitas são reunidos aos formulários de cada caso, compondo o prontuário em que os funcionários também registram sistematicamente todas as idas de familiares daquele desaparecido ao serviço, anotando a data e o horário em que ocorreram, se houve entrega de mais cópias de cartazes para divulgação "por conta própria" e eventuais detalhes sobre o que teria sido conversado entre familiares e funcionários em cada ocasião. 
As anotações do prontuário em nome de William, um bebê desaparecido em 1997 na zona portuária da cidade do Rio de Janeiro, demonstra que as idas dos familiares ao serviço pode ser algo não só regular, mas também ritmado. Eduardo, camelô, morador de rua e pai do menino, esteve lá pela primeira vez no dia seguinte ao desaparecimento do filho. Ele não possuía alguns dos documentos requisitados no serviço para que o caso fosse cadastrado, mas levou consigo tudo o que tinha e uma foto do garoto. Apesar da falta de documentação, um prontuário foi excepcionalmente aberto em nome de William, em mais uma das acolhedoras "exceções" que acontecem ali, e o retrato passou a ser divulgado em cartazes e outros materiais. Dois anos depois, já em 1999, Eduardo voltou ao serviço e apresentou novos documentos, que tinha obtido naquele intervalo de tempo. Nenhum funcionário do serviço os havia solicitado naquele ínterim, mas o pai de William apresentou cada um deles, que foram fotocopiados e anexados ao prontuário. Na ocasião, Eduardo perguntou se havia novidades sobre o caso, questionamento que ficou registrado nos papéis. Não havia. A partir daquela data, sempre com a mesma resposta sobre a inexistência de novidades, Eduardo foi ao serviço regularmente a cada quatro ou cinco meses. Fez isso até o ano de 2007, quando faleceu sem ter tido qualquer notícia do paradeiro de seu filho.

Assim como registram cada uma das idas dos familiares ao serviço, os assistentes sociais e demais profissionais que lá trabalham anotam também as eventuais "denúncias" geradas pela divulgação dos retratos em cartazes e demais materiais gráficos distribuídos pelo país. Tais "denúncias" consistem em informações aportadas por telefonemas, cartas ou e-mails de pessoas que afirmam ter tido notícias ou visto pessoalmente alguma das crianças cujas fotos conheceram através do material divulgado pelo serviço. O mais frequente, porém, é que os prontuários não registrem nenhuma "denúncia", mesmo em casos divulgados pelo serviço com regularidade há muitos anos. O caso de William, por exemplo, não teve nenhuma denúncia registrada nos dez anos que separam o desaparecimento do menino e a morte de seu pai.

Enquanto realizava trabalho de campo no serviço, vi essa ausência de "denúncias" característica da maior parte dos casos cadastrados lá ser alterada. 
Naquele período, uma novela de um canal da televisão aberta tinha, em seu enredo, a história de uma criança desaparecida. A emissora de televisão que veiculou a novela firmou então uma parceria com o serviço, tendo tomado duas medidas: inserido uma fala de Gustavo, gerente do serviço, em um dos capítulos do folhetim, em uma cena que simulava um atendimento realizado em uma repartição construída na novela para reproduzir o funcionamento do serviço; e a divulgação regular de retratos das crianças e adolescentes cujos casos estão cadastrados lá ao final de cada capítulo diário da novela. Foi um longo período em que a divulgação das fotos via cartazes e outros materiais impressos ganhou um reforço considerável, passando a ser divulgadas por meio audiovisual. Foi também um período em que as "denúncias" sobre os casos aumentaram consideravelmente, fazendo com que o telefone do serviço tocasse muito mais do que de costume e que novas anotações fossem feitas pelos funcionários nos prontuários dos casos. A percepção dos assistentes sociais e demais funcionários sobre a rotina do serviço naquela época era sintetizada em frases - ditas entre eles e também diretamente para mim - que me marcaram, por exemplo: “Tá tendo muito mais trabalho, hein?"; "Esse telefone não para mais de tocar!"; "Não está dando pra fazer hora, não".

A capacidade que a divulgação das fotos pela televisão teve de gerar "mais trabalho", aumentar as anotações nos prontuários e fazer com que o telefone do serviço tocasse com mais frequência foi algo que me chamou atenção para mais uma incidência do tempo e da sua relação com a rotina e o sofrimento em casos de desaparecimento geridos no estado do Rio de Janeiro. Esse aumento de uma relativa urgência no trabalho a ser feito, tornando impossível "fazer hora" em função do aumento das "denúncias" que chegavam ao serviço, me chamou atenção para o evidente contraste entre aquela aceleração extraordinária do cotidiano dos funcionários e o ritmo calmo do dia a dia do serviço, marcado por pouquíssimos telefonemas e pelo atendimento regular a familiares que frequentavam a casa, buscavam cartazes e pediam sistematicamente informações sobre os casos, como fez Eduardo, o pai de William, até o final de sua vida, mas que não se mostravam capazes de gerar a sensação de "muito trabalho". 
Comparar o ritmo do cotidiano mais regular do serviço com a aceleração provocada pela divulgação dos retratos na novela indica, a meu ver, algo central sobre a gestão dos desaparecimentos de pessoas naquela repartição: a possibilidade de imprimir urgência a um caso, mesmo em um serviço "acolhedor", que abre exceções e que é visto com bons olhos por familiares de desaparecidos é algo que está fora das capacidades desses sujeitos. O que a novela foi capaz de fazer contrasta muito, em sua velocidade e na sensação de urgência que imprimiu nos funcionários, com o ritmo do cotidiano de atendimentos que tem seus contornos definidos pelas visitas regulares e ritmadas dos familiares que frequentam a casa, buscam material e sistematicamente pedem notícias sobre os casos dos seus filhos e parentes. A produção da urgência, nesse sentido, revela-se fora do alcance dos familiares de desaparecidos, a quem seria difícil - senão impossível - incidir sobre a velocidade e o volume do trabalho desempenhado ali. Confirma, nesse sentido, o processo de que fala Ayuero (2011): situações e modalidades de espera impostas em repartições públicas podem provocar efeitos de dependência e subordinação, além de reproduzir uma noção de cidadania forjada na submissão.

\section{CONSIDERAÇÕES FINAIS}

Como argumentam Ferguson e Gupta (2002), as práticas cotidianas de instituições estatais têm importantes efeitos em termos da produção de ordens espaciais e hierarquias escalares, razão pela qual podem ser analisadas como "rituais mundanos da espacialização do Estado" (p. 984). Para os autores, a operação rotineira de instituições estatais alimenta percepções do Estado como entidade não só reificada, mas superior e abrangente em relação a quaisquer outras instituições e centros de poder. Cotejados com meus dados de pesquisa sobre o que se passa "do lado de lá" dos balcões de repartições policiais e assistenciais que lidam com casos de desaparecimento de pessoas, os argumentos dos autores sobre percepções espaciais do Estado inspiram um movimento análogo: que analisemos as percepções temporais daquela mesma entidade 
imaginada - percepções estas que, no tocante a casos de desaparecimento, são inseparáveis de experiências de sofrimento. Nesse sentido, a reflexão aqui apresentada, circunscrita ao universo da administração de casos de desaparecimento por instituições estatais, permite sugerir que as práticas e procedimentos adotados em repartições e serviços policiais e assistenciais aonde peregrinam regularmente familiares de desaparecidos têm efeitos em termos de suas percepções temporais do Estado.

No artigo citado, Ferguson e Gupta tratam da peregrinação de auditores por certos programas sociais indianos, e revelam a percepção de funcionários atuantes nesses programas - os que são imediatamente auditados - do que seja o Estado. Neste artigo, busquei tratar da peregrinação de familiares de desaparecidos por instituições diversas e, analogamente, iluminar sua percepção temporal do que seja o Estado, levando a sério a sugestão de Bourdieu (2001, p. 279) de que "a espera é uma das maneiras privilegiadas de experimentar o poder e o vínculo entre o tempo e o poder". A partir dos dados etnográficos sobre a gestão policial e assistencial de casos de desaparecimento apresentados ao longo do texto, parece-me pertinente afirmar, a título de encerramento da reflexão aqui proposta, que tal percepção é indissociável da própria espera pelo desaparecido, vivida como experiência intensa de sofrimento. Mais ainda, parece-me pertinente sugerir que, em termos analíticos, vale a pena pensar não só em percepções, mas em experiências de Estado que são, inextricavelmente, experiências de sofrimento.

Para qualificar melhor essas experiências de Estado, o conceito de banalidade do poder proposto por Achille Mbembe (1992) revela-se bastante potente. Para o autor, interessado no lugar do grotesco, do obsceno e do que chama de "estética da vulgaridade" no mundo pós-colonial, devemos compreender a banalidade do poder estatal, entendida como parte de um regime de violência particular, como mais do que o resultado da multiplicação e rotinização de formalidades burocráticas e regras arbitrárias, implícitas ou explícitas, em determinados contextos. Para além disso, o caráter banal (e por isso mesmo violento e excessivo) do poder estatal pode relacionar-se diretamente com a ideia de previsibilidade, remetendo a gestos e ações ritmados e repetidos, ainda 
que excessivos, grotescos e vulgares. Trata-se, enfim, de algo inscrito na ordem da experiência temporal, regular e ritmada do conjunto de instituições, autoridades, práticas e regras entendidas como encarnações do Estado por parte de sujeitos (e populações, como trata o autor).

Convidadas para encerrar a reflexão sobre a gestão policial e assistencial de casos de desaparecimento que apresentei aqui, essas ideias permitem sugerir que, nesses "casos", a peregrinação de familiares de desaparecidos por instituições diversas, o escrutínio moral a que são submetidos, o regime de ação extenuante que constitui a espera que passa a caracterizar suas vidas e a impossibilidade de incidir sobre a urgência dos casos são parte de uma experiência temporal do Estado, que é, ao mesmo tempo e inextricavelmente, a própria experiência de sofrimento de ter um filho, parente ou companheiro desaparecido. Se é assim no universo dos desaparecimentos, talvez também o seja em outras experiências de sofrimento que levam sujeitos a diferentes repartições públicas em busca de atendimento, direitos e justiça, articulando de modo estreito e decisivo sua vida, biografias e famílias às suas relações com o Estado.

\section{REFERÊNCIAS BIBLIOGRÁFICAS}

1. ARAÚJO, Fábio Alves. Falta alguém na minha casa. In: KANT DE LIMA, Roberto. Antropologia e direitos humanos 5. Brasília, DF: Booklink: Fundação Ford, 2008. p. 166-225.

2. ARAÚJO, Fábio Alves. Das "técnicas" de fazer desaparecer corpos: desaparecimentos, violência, sofrimento e política. Rio de Janeiro: Lamparina: Faperj, 2014.

3. AYUERO, Javier. Patients of the state: an ethnographic account of poor people's waiting. Latin American Research Review, Baltimore, v. 46, n. 1, p. 5-29, 2011.

4. BIRMAN, Patricia. Movimentos cívico-religiosos no Rio de Janeiro e alguns de seus impasses: o caso do mural da dor. In: BIRMAN, Patricia; LEITE, Márcia Pereira (org.). Um mural para a dor: movimentos cívico-religiosos por justiça e paz. Porto Alegre: UFRGS, 2004. p. 221-226.

5. BOURDIEU, Pierre. Meditações pascalinas. Rio de Janeiro: Bertrand Brasil, 2001. 
6. DAS, Veena. Critical events: an anthropological perspective on contemporary India. Nova York: Oxford University Press, 1995.

7. DAS, Veena. Life and words: violence and the descent into the ordinary. Berkeley: University of California Press, 2007.

8. FARIAS, Juliana. Da capa de revista ao laudo cadavérico: pesquisando casos de violência policial em favelas cariocas. In: BIRMAN, Patricia et al. Dispositivos urbanos e trama dos viventes: ordens e resistências. Rio de Janeiro: Editora FGV: Faperj, 2015. p. 419-449.

9. FERGUSON, James; GUPTA, Akhil. Spatializing states: toward an ethnography of neoliberal governmentality. American Ethnologist, Ann Arbor, v. 29, n. 4, p. 981-1002, 2002.

10. FERREIRA, Letícia Carvalho de Mesquita. Pessoas desaparecidas: uma etnografia para muitas ausências. Rio de Janeiro: Editora UFRJ, 2015a.

11. FERREIRA, Letícia Carvalho de Mesquita. Formalidades, moralidades e disputas de papel: a administração de casos de crianças desaparecidas no Rio de Janeiro. Dilemas: revista de estudos de conflito e controle social, Rio de Janeiro, v. 8, n. 2, p. 207-234, 2015b.

12. FRANÇA, Paula Marcela Ferreira. “Onde está meu filho?”: a denúncia do desaparecimento de pessoas. 2018. Tese (Doutorado em Sociologia) - Faculdade de Ciências Sociais, Universidade Federal de Goiás, Goiânia, 2018.

13. GATTI, Gabriel. De un continente al otro: el desaparecido transnacional, la cultura humanitaria y las víctimas totales en tiempos de guerra global. Política y Sociedad, Madrid, v. 48, n. 3, p. 519-536, 2011.

14. HOGBEN, Susan. Life's on hold: missing people, private calendars and waiting. Time \& Society, Thousand Oaks, n. 15, p. 327-342, 2006.

15. JARDIM, Tarciso Dal Maso. Brasil condenado a legislar pela Corte Interamericana de Direitos Humanos: da obrigação de tipificar o crime de desaparecimento forçado de pessoas. Brasília, DF: Senado Federal, 2011. (Textos para discussão, n. 83).

16. JEGANATHAN, Pradeep. Checkpoint: anthropology, identity, and the state. In: DAS, Veena; POOLE, Deborah (ed.). Anthropology in the margins of the state. Santa Fé: School of American Research Press, 2004. p. 67-80.

17. KLEINMAN, Arthur; DAS, Veena; LOCK, Margareth. Introduction. In: KLEINMAN, Arthur; DAS, Veena; LOCK, Margaret (ed.). Social suffering. Berkeley: University of California Press, 1997. p. I-XXVII.

18. LACERDA, Paula. Meninos de Altamira: violência, luta política e administração pública. Rio de Janeiro: Garamond, 2015. 
19. LAMPINEN, James Michael; ARNAL, Jack; HICKS, Jason. The effectiveness of supermarket posters in helping to find missing children. Journal of Interpersonal Violence, Thousand Oaks, v. 24, n. 3, p. 406-423, 2008.

20. LEAL, Eduardo Martinelli. A dúvida mais persistente: as formas de governo do desaparecimento de pessoas no Brasil. 2017. Tese (Doutorado em Antropologia Social) - Universidade Federal do Rio Grande do Sul, Porto Alegre, 2017.

21. MBEMBE, Achille. The banality of power and the aesthetics of vulgarity in the postcolony. Public Culture, Durham, v. 4, n. 2, p. 1-30, 1992.

22. OLIVEIRA, Dijaci David. Desaparecidos civis: conflitos familiares, institucionais e de segurança pública. 2007. Tese (Doutorado em Sociologia) - Instituto de Ciências Sociais, Universidade de Brasília, Brasília, DF, 2007.

23. OLIVEIRA, Sandra Rodrigues de. Onde está você agora além de aqui, dentro de mim? O luto das mães de crianças desaparecidas. 2008. Dissertação (Mestrado em Psicologia) - Departamento de Psicologia, Pontifícia Universidade Católica do Rio de Janeiro, Ri ode Janeiro, 2008.

24. RIO DE JANEIRO. Lei n. 3.614, de 18 de julho de 2001. Determina à autoridade policial e aos órgãos de segurança pública a busca imediata de pessoa desaparecida menor de 16 (dezesseis) anos ou pessoa de qualquer idade portadora de deficiência física, mental e/ou sensorial. Diário Oficial do Estado do Rio de Janeiro, Rio de Janeiro, 31 jul. 2001.

25. SHARMA, Aradhana; GUPTA, Akhil. Introduction: rethinking theories of the state in an age of globalization. In: SHARMA, Aradhana; GUPTA, Akhil (ed.). The anthropology of the State: a reader. Malden: Blackwell, 2006. p. 1-41.

26. SOUZA LIMA, Antonio Carlos de (org.). Gestar e gerir: estudos para uma antropologia da administração pública no Brasil. Rio de Janeiro: NuAP: Relume Dumará, 2002.

27. VIANNA, Adriana. Tempos, dores e corpos: considerações sobre a "espera" entre familiares de vítimas de violência policial no Rio de Janeiro. In: BIRMAN, Patricia et al. (org.). Dispositivos urbanos e trama dos viventes: ordens e resistências. Rio de Janeiro: Editora FGV: Faperj, 2015. p. 405-418.

28. VIANNA, Adriana; FARIAS, Juliana. A guerra das mães: dor e política em situações de violência institucional. Cadernos Pagu, Campinas, n. 37, p. 79-116, 2011. 